\title{
Caracterización socioeconómica de los estudiantes matriculados en primer semestre en la Universidad Libre seccional Cali, Período 2015-2*
}

\section{Caracterização socioeconômica dos estudantes inscritos no pirmeiro semestre na Universidad Libre - Cali, 2015 - 2 periodo}

\section{Socioeconomic charaterization of students enrolled in first semester at the Universidad Libre - Cali, 2015-2 period}

\author{
Héctor Darío Zapata-González \\ Economista, Universidad de Antioquia. Docente del programa de Economía Universidad Libre Cali, Colombia
} hector.zapata@unilibrecali.edu.co

\begin{abstract}
Harold Adolfo Erazo-Barona
Magister en Ciencias Financieras y de Sistemas, Universidad Central. Director Seccional de Planeación y Docente del programa de Administración Universidad Libre Cali, Colombia

haerazo@gmail.com
\end{abstract}

\section{Mayra Alejandra Ortiz-Bueno}

Estudiante programa de Economía - Auxiliar de investigación. Universidad Libre Cali, Colombia.

\begin{abstract}
Resumen
El artículo hace referencia a las características sociales, económicas y educativas de los estudiantes que ingresan en 2015-2 a la Universidad Libre Seccional Cali al primer semestre de cualquiera de sus diez programas de educación superior ofrecidos. En Colombia, en cumplimiento de la normatividad nacional, las instituciones y programas académicos de educación están llamados a suministrar información relevante, confiable y oportuna al Sistema Nacional de Información de la Educación Superior (SNIES), donde se recopila y organiza la información sobre la educación superior que permite hacer planeación, monitoreo, evaluación, asesoría, inspección y vigilancia del sector, como soporte para la gestión de planeación y seguimiento a los planes de mejoramiento de las Instituciones de Educación Superior (IES).
\end{abstract}

\footnotetext{
* Cómo citar: Zapata-González H.D.; Erazo-Barona H.A.; Ortiz-Bueno M.A. (2016). Caracterización socioeconómica de los estudiantes matriculados en primer semestre en la Universidad Libre seccional Cali Período 2015-2. Revista Libre Empresa. 13(1), 35-60. http://dx.doi.org/10.18041/libemp.2016. v13n1.25101
} 


\section{Palabras clave}

Educación, sistema de información educativa, planeación, matriculados.

\section{Abstract}

The following writing refers to the social, economic and educational characteristics of students entering in 2015-2 at the Universidad Libre Seccional-Cali to the first semester of any of its ten higher education programs offered. In Colombia, in compliance with national regulations, institutions and academic education programs are called to provide relevant, reliable and timely information to the National Information System for Higher Education (NISHE), where it collects and organizes information about higher education that allows planning, monitoring, evaluating, consulting, inspection and supervision of the sector as support for management planning and monitoring plans of the Higher Education Institutions (HEI).

\section{Keywords}

Education, education information system, planning, enrolled.

\section{Resumo}

O artigo referese às características sociais, econômicas e educacionais dos alunos que entram 2015-2 na Universidad Libre Seccional Cali no primeiro semestre de qualquer um dos seus dez programas de educação superior oferecidos. Na Colômbia, em conformidade com as normas nacionais, instituições e programas de educação acadêmicos são chamados a fornecer informações relevantes, confiáveis e oportunas para o Sistema Nacional de Informação do Ensino Superior (SNIES), onde recolhe e organiza as informações sobre a educação superior que permite que a indústria de planejamento, acompanhamento, avaliação, avaliação, controlo e vigilância, tais como suporte para o planejamento de gestão e monitoramento de planos de melhoria de instituições de ensino superior (IES).

\section{Palavras chave}

Educação, sistema de informação de educação, planejamento, inscrita.

\section{Introducción}

El objetivo de este trabajo es encontrar los aspectos sociales, económicos y de educación de los estudiantes matriculados en la Universidad Libre, Seccional Cali en el período de 2015-2, como un aporte para el diseño de mejores estrategias educativas y de la oferta de bienestar universitario, incluso, para implementar normas públicas, pues en la ciudad de Cali se tiene un Sistema de Transporte Masivo (MIO), que puede mejorar su programación de nuevas rutas conociendo la geo-referenciación de los estudiantes de esta Universidad, más aún, cuando esta Seccional se apresta a ocupar un nuevo campus construido al sur de la ciudad, lo que demanda más finos insumos de planeación en sus aspectos académicos y locativos. 
En el mundo académico existe gran interés por conocer las características de los estudiantes que ingresan a los centros educativos. En Colombia, en cumplimiento de la normatividad nacional, ${ }^{1}$ las instituciones y programas académicos de educación están llamados a suministrar información relevante, confiable y oportuna al Sistema Nacional de Información de la Educación Superior (SNIES), donde se recopila y organiza la información sobre la educación superior que permite hacer planeación, monitoreo, evaluación, asesoría, inspección y vigilancia del sector, como soporte para la gestión de planeación y seguimiento a los planes de mejoramiento de las Instituciones de Educación Superior (IES).

En Europa, como resultado de un acuerdo entre los gobiernos que la conforman, las instituciones de educación han asumido un papel principal en la construcción del Área Europea de Educación Superior, que apunta a desarrollar en la dirección de los principios del pacto de Bolonia (Carta Magna de la Universidad de Bolonia de 1988). Allí los propósitos van desde cambios curriculares y homologación europea de títulos, hasta la revisión de los modelos de financiación universitaria, pasando por la instauración de nuevas metodologías docentes y la enseñanza práctica basada en las Técnicas de la Información y la Comunicación (TIC).

El objetivo del proyecto origen del artículo es caracterizar el perfil socioeconómico predominante entre los estudiantes de primer semestre de pregrado, que ingresaron en el 2015-2 de la Universidad Libre Seccional Cali.

\section{Estado del arte}

De acuerdo con la disponibilidad de información publicada en revistas y/o en la web, relacionamos a continuación los principales trabajos encontrados.

La Pontificia Universidad Javeriana de Cali, en su estudio titulado: "Voces y Rostros de Jóvenes Javerianos” Mora, García y Galeano (2000) realizan una metodología en la que integran la perspectiva cualitativa y la perspectiva cuantitativa (encuesta), con variables: Sociodemográfico y cultural; Académico y Cognoscitivo; Socioafectivo y Sexual; Ético, Moral y Religioso; Participativo y Gremial; Político e Ideológico; Salud; Uso del Tiempo Libre y Deportivo.

En la Fundación Universitaria del Área Andina seccional Pereira, se realizó un estudio con 147 estudiantes (Centro de Investigaciones-Departamento de Bienestar Universitario, 2004), donde se recolectó información relacionada con aspectos socioeconómicos, académicos, socioculturales, familiares y de proyección personal para el segundo semestre del 2004, la Fundación Universitaria del Área Andina seccional Pereira, realizó entrevistas al momento de ingresar a la institución y, entre los principales resultados, se encontró que los estudiantes de primer semestre en un porcentaje alto son adolescentes y adultos jóvenes entre 16-23 años. Uno de cada 3 trabaja; son padres o madres de familia el 59.5\%, porcentaje que se incrementa especialmente con los estudiantes de enfermería grupo B; el 41\% ingresó a la Institución luego de 2 años o más de haber terminado su bachillerato; uno

1 Ley 30 de diciembre 28 de 1992, Decreto 1767 de 2006, Decreto 4968 de diciembre 23 de 2009 y Resolución 1789 de 2010, entre otras. 
de cada 3 estudiantes se encuentra laborando al inicio de su carrera; aproximadamente el $50 \%$ procede de familias de estrato medio bajo.

La Universidad EAFIT de Medellín realiza el "Perfil Socioeconómico del estudiantado de EAFIT" (Acevedo y Jaramillo,2007), donde señala que los factores sociodemográficos y económicos marcan la vida de los individuos y generan características comunes en grupos sociales, siendo factible reconocer la identidad de una comunidad específica. Aplican la encuesta a 2048 estudiantes que participan voluntariamente y con la información recolectada, plantearon propuestas de mejoramiento para garantizar la satisfacción de los estudiantes.

La Universidad de Caldas realizó el perfil socioeconómico y demográfico de acceso a la carrera de Antropología y Sociología, Genecco, Díaz, Raigosa y Marulanda (2007), compuesto por la primera parte descriptiva, en el que los datos concernientes arrojaron las condiciones socioeconómicas, demográficas y las motivaciones de ingreso y permanencia en la carrera de los estudiantes y, una segunda parte, orientado a la realización de lecturas sociológicas del perfil a la luz de la carrera bourdeana de capital cultural y su relación con el origen social de los estudiantes. En el artículo los resultados exponen la composición social media y baja de los estudiantes, las actividades a que se dedican en su tiempo libre, las motivaciones de permanencia y la ubicación sociodemográfica de la mayor parte de los integrantes de cada programa.

En el 2009 se realizó la Caracterización de los estudiantes de la Universidad de Cundinamarca para el diseño de un modelo de bienestar universitario (Orduz, 2009), en la investigación cualitativa participativa, identificaron particularidades de los estudiantes que ayudaron a diseñar un modelo para dar respuesta a las necesidades de la población institucional, como apoyo financiero, propuestas para el uso libre, entre otras.

La Universidad Autónoma de Occidente en el año 2007 (Oficina de Planeación y Desarrollo Institucional- Bienestar Universitario, 2007), analiza los siguientes grupos de variables: 1. Variables Demográficas, 2. Variables Biográficas, 3. Variables Socioeconómicas, 4. Variables Académicas y 5. Variables relacionadas con el uso del tiempo libre. De la investigación se logra identificar las principales características del perfil socioeconómico del estudiante uniautónomo, encontrando una significativa prevalencia para la edad de 15 a 25 años, donde la mayoría de la población presenta estado civil soltero, la mayor parte son originarios del Valle del Cauca y dentro de estos la mayoría, provenientes de Santiago de Cali, el 60\% está repartida en los estratos 3 y 4, la mayoría trabaja y terminaron los estudios de bachillerato en colegio privado laico.

La Universidad de Pamplona (Norte de Santander) (Oficina de Planeación, 2012), realizó un documento descriptivo con enfoque mixto en el que identificó las condiciones socioeconómicas de los estudiantes de pregrado desde la perspectiva demográfica, social y económica de los estudiantes de pregrado matriculados en las sedes de Pamplona, Cúcuta y Villa del Rosario, tomando una muestra representativa de 1.633 estudiantes que ingresaron en el primer semestre del año 2012; el documento permitió analizar que los estudiantes eran 
provenientes de la estratos 1 y 2 y que las fuentes de financiamiento son sustentadas por los ingresos familiares o propios, la finalidad de la investigación era promover políticas internas y alternativas de acción de acuerdo con las necesidades de la comunidad estudiantil.

La Oficina de Planeación de la Universidad Nacional de Colombia, sede Medellín, realizó el perfil socioeconómico de los estudiantes del segundo semestre del 2005 (Rico, 2005). Se invitó a los 8.980 estudiantes matriculados a diligenciar el formulario web de la encuesta, obteniendo respuesta positiva por parte de 3.517 estudiantes, la Universidad tiene una secuencia de la investigación iniciada en 1992, luego en 1996 y 2000, se realizaron los tres anteriores perfiles socioeconómicos de los estudiantes. Uno de los propósitos desde la realización del segundo y tercer perfil fue darle continuidad a este trabajo actualizando el trabajo periódicamente.

La Universidad Libre ha tenido algunos acercamientos con investigaciones para caracterizar la población estudiantil, por ejemplo, en la Seccional Barranquilla se realizó un artículo, en el que presenta los resultados del Estudio Socioeconómico de los estudiantes del Programa de Ingeniería Industrial en el periodo académico 2012-2 (Campos, 2012), en el marco del proceso de autoevaluación y autorregulación, documento realizado para la renovación del registro calificado ante el Ministerio de Educación Nacional (MEN), logrando una cobertura del 90.8\% con el fin de formular estrategias en el Plan Integral de Mejoramiento Institucional (PIDI) y en el Plan de Acción Anual del Programa de Ingeniería Industrial. En la Seccional Cali con la coordinación del Programa de Economía con énfasis en Negocios Internacionales (García, 2007), realizó una investigación para identificar el perfil socioeconómico de los estudiantes que ingresaron a los diferentes programas de pregrado en el primer semestre del 2007 con una muestra de 374 estudiantes. En esta investigación se hace la comparación entre instituciones de educación superior en Colombia y se toman variables como la edad, sexo, estado civil, situación de convivencia, variables socioeconómicas y académicas, proporcionando recomendaciones para la institución como la elaboración de estrategias de mercadeo para alcanzar mayor bienestar de los estudiantes.

\section{Método}

El presente informe es de naturaleza descriptiva, se elaboró a partir de la información recolectada en una base de datos con el apoyo de una tabla dinámica diseñada en Excel que recibe los resultados de la aplicación de un formulario de encuesta auto-aplicado, cuyo diligenciamiento se realizó a los estudiantes por medio de la página web de la Universidad, para lo cual se dispuso de tres salas de cómputo dotadas cada una con 20 computadores que operaban dentro del horario de clases, tanto en las mañanas como en la noche durante un mes.

Elaplicativo está ubicado en www.unilibrecali.edu.co/admisiones/datoscomplementarios, y sus preguntas provienen de los datos solicitados por el Ministerio de Educación en el Sistema Nacional de Educación Superior (SNIES), consta de dos partes, el formulario de encuesta y una tabla dinámica Excel que permite cruce de variables y los cálculos y gráficos de este paquete. 
Los estudiantes fueron invitados a realizar la encuesta mediante visitas personalizadas a los salones de clase por parte de los autores de este informe, quienes debían orientarles en el diligenciamiento del formulario.

El universo de la población estudiantil es de 630 matriculados en los diferentes programas académicos, respondiendo el 69\%, es decir 434 estudiantes.

\subsection{Población y Muestra}

El total de la población está conformado por el número de estudiantes que cancelaron la matrícula de los programas de pregrado de la Universidad Libre Seccional Cali en el periodo $2015-2^{2}$.

Para conocer el tamaño de la muestra se utilizaron los datos emitidos por el SNIES y se calculó la siguiente formula estadística:

$$
n=\frac{Z^{2} * N * p * q}{\left(\left(e^{2} *(N-1)\right)+\left(Z^{2} * p * q\right)\right.}
$$

Donde:

: Tamaño de la muestra $=239$

: Valor de sigma asignado para un nivel de confianza del 95\% para la población. $(\mathrm{z}=1,96)$

: Tamaño de la población $=630$

: Probabilidad de que un estudiante sea seleccionado, donde $\mathrm{p}=0,5$

: Probabilidad de que un estudiante no sea seleccionado, donde $q=1-p=0,5$

: Error asociado a la muestra $=5 \%$

Sin embargo, se presentó una respuesta voluntaria por parte de los estudiantes que desarrollaron la encuesta, los cuales llevan a realizar análisis sobre un total de 434 estudiantes, siendo aproximadamente el 69\%.

\subsection{Variables consideradas}

El perfil se elaboró con las siguientes variables:

- Demográficas: Departamento de nacimiento y ciudad de residencia, género, estado civil, vivienda (propia o alquiler), nivel educativo alcanzado por los familiares, personas a cargo del estudiante y religión.

- Socioeconómicas: Estrato, financiación de estudios, situación laboral, seguridad social, transporte y dedicación en el tiempo libre.

- Antecedentes académicos: Carácter de la Institución en la que cursó bachillerato y fecha de grado, ICFES, títulos obtenidos antes de entrar a estudiar pregrado y capacidades excepcionales.

2 Se tuvo presente la fecha límite para cancelar el valor de la matrícula, cerrando los programas el 28 de agosto del 2015, a excepción de la Facultad de Derecho que cerró el 7 de septiembre. De acuerdo con esto, se solicitó el 8 de septiembre el listado a Registro Académico. 


\section{Resultados generales}

A continuación se presentan los resultados analizados de la encuesta de los estudiantes matriculados en primer semestre para el periodo 2015-2.

\subsection{Variables demográficas}

\subsubsection{Departamento de nacimiento y ciudad de residencia}

Del $80 \%$ de los estudiantes que aporta el Valle del Cauca en 2015-2, provienen principalmente de los Municipios de Cali 84\%, Buenaventura 4\%, Palmira 3\%, Florida 2.3\%; y los municipios que presentan mayor disminución del número de estudiantes son Cali, Palmira, Buga y Tuluá. Presentan aumento Florida y Jamundí.

Las carreras más demandadas por estudiantes de fuera del Valle del Cauca en 2015-2 fueron Derecho, Contaduría, y Medicina, pues el 26\% de los estudiantes provenientes del departamento del Cauca, 9 han elegido el programa de Derecho, 8 Contaduría, 5 Medicina, 3 Enfermería y uno Administración de Empresas. De los 16 provenientes de Nariño, 6 ingresan a Medicina y 5 Derecho. De los 8 de Caldas 3 eligieron Contaduría y 2 Derecho.

Comparando el departamento de nacimiento (de procedencia), en la consulta realizada en 2014-2 y 2015-2, se observa una disminución de matriculados principalmente en los departamentos de: Valle del Cauca (-17\%), Cauca (-26\%), Nariño (-33\%), Quindío (-86\%), Antioquia (-63\%). Presentan variación positiva los departamentos de Bolívar, Caldas, Cundinamarca, Huila y Santander, (ver Figura 1).

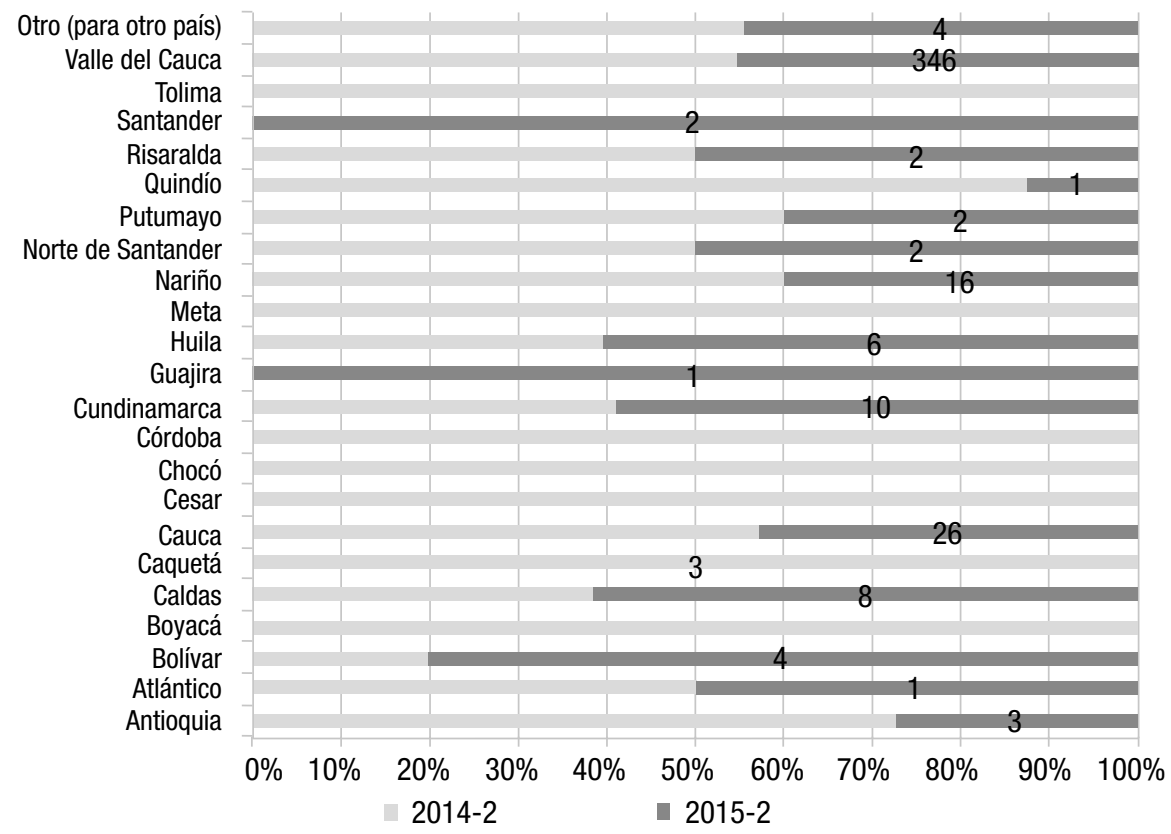

Figura 1. Departamento de nacimiento comparativa 2014-2 y 2015-2

Fuente: Encuesta estudiantes de pregrado primer semestre, período 2014-2 y 2015-2, cálculos propios 
Similar comportamiento se observa en las respuestas de los estudiantes provenientes del exterior. De los 4 que respondieron haber nacido en otro país, dos (nacidos en Rio de Janeiro, San Martín) eligieron Medicina y dos nacidos en New York; Medicina y Derecho.

En 2014-2 también llegaron cuatro estudiantes extranjeros, uno para Derecho nacido en Carabobo (Venezuela), uno para Ingeniería Industrial de Nijegen (Países Bajos) y dos para Medicina (San José -Costa Rica, USA).

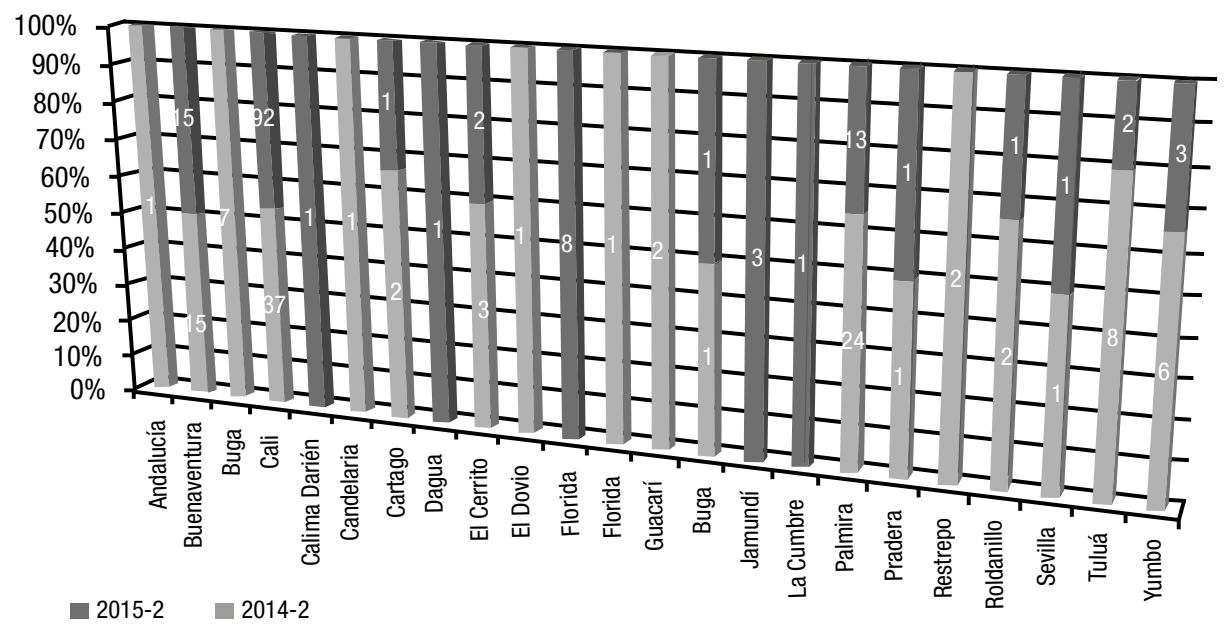

Figura 2. Ciudad de residencia comparativa 2014-2 y 2015-2

Fuente: Encuesta estudiantes de pregrado primer semestre, período 2014-2 y 2015-2, cálculos propios

\subsubsection{Vivienda por Sector y Comunas en Cali}

La ubicación de la vivienda de los estudiantes encuestados tiene su mayor concentración en el sector Sur, 36\%; en el que sobresalen dos comunas, la 17 (13\%), conformada por los barrios Valle Lili, Caney, Capri, Limonar, La Hacienda entre otros; y la comuna 19 con 52 estudiantes, 12\% compuesta por los barrios San Fernando, El Lido, Los Cámbulos, Bellavista, Miraflores, Santa Isabel, entre otros. Es seguido por el sector nororiental (24\%) con mayor periodicidad en la comuna 6 y 4 , en los sectores oriente y noroccidente de Cali habitan el 11\% y $8 \%$ respectivamente; cerca del $9 \%$ en el Distrito de Aguablanca (comuna 13, 14, 15 y 21), estos resultados se visualizan en la Figura 3, donde el Nororiente toma el color azul, el Noroccidente amarillo, el Sur verde, Oriente café y se marca de naranja el Distrito de Agua Blanca. 


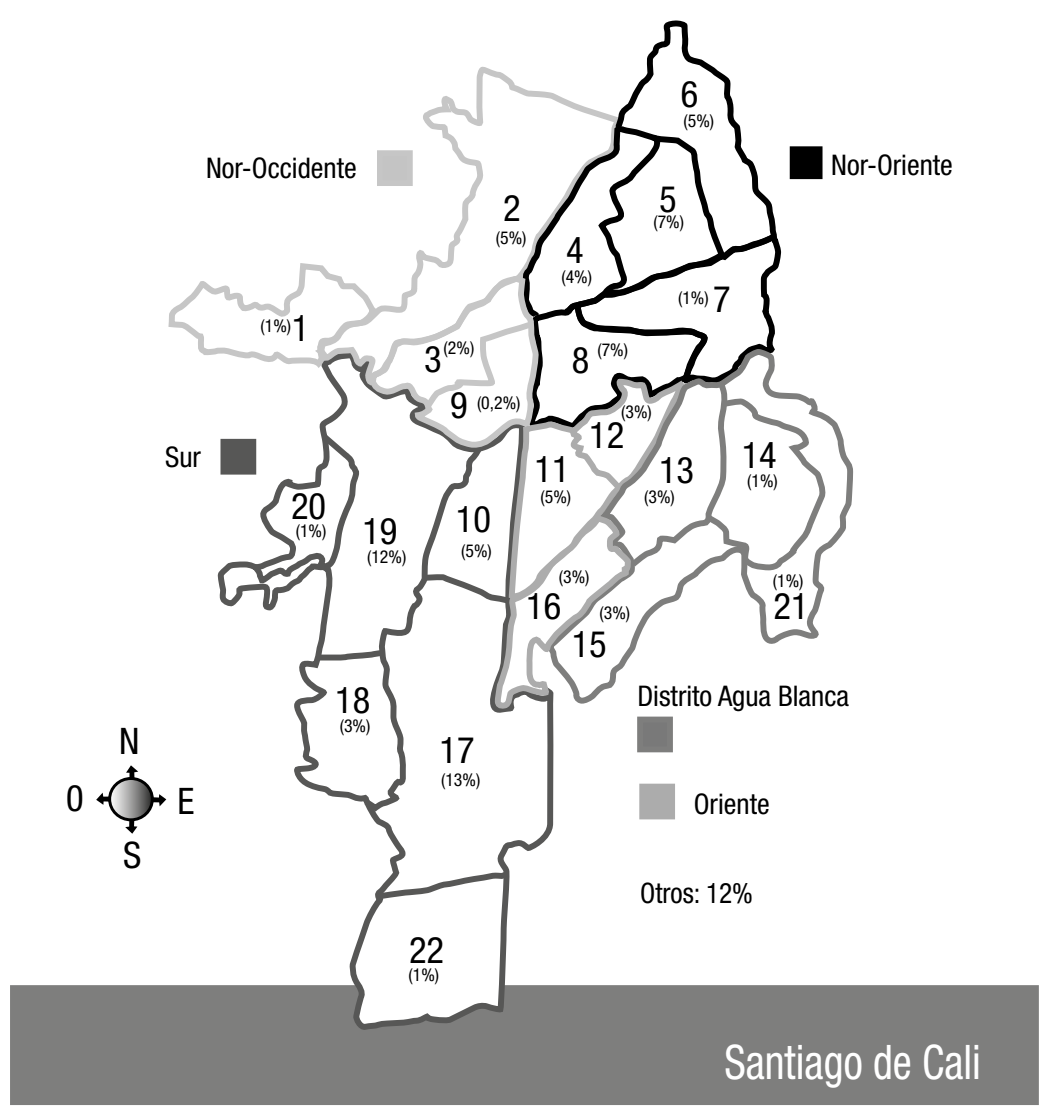

Figura 3. Mapa por Comunas de la vivienda de estudiantes en Cali

Fuente: Encuesta estudiantes de pregrado primer semestre, período 2015-2, cálculos propios

La Figura 4 presenta los programas de la Facultad de Ciencias Económicas, Administrativas y Contables. El programa de Administración de Empresas donde la mayor frecuencia se presenta en la comuna 19 con una representación para el programa del 15\%, seguido por la 17 (13\%) y las comunas 5 y 8 con el (10\%) cada una, acumulando aproximadamente el $50 \%$ de los encuestados. Del Distrito de Aguablanca se desplazan a la Universidad 6 estudiantes. 


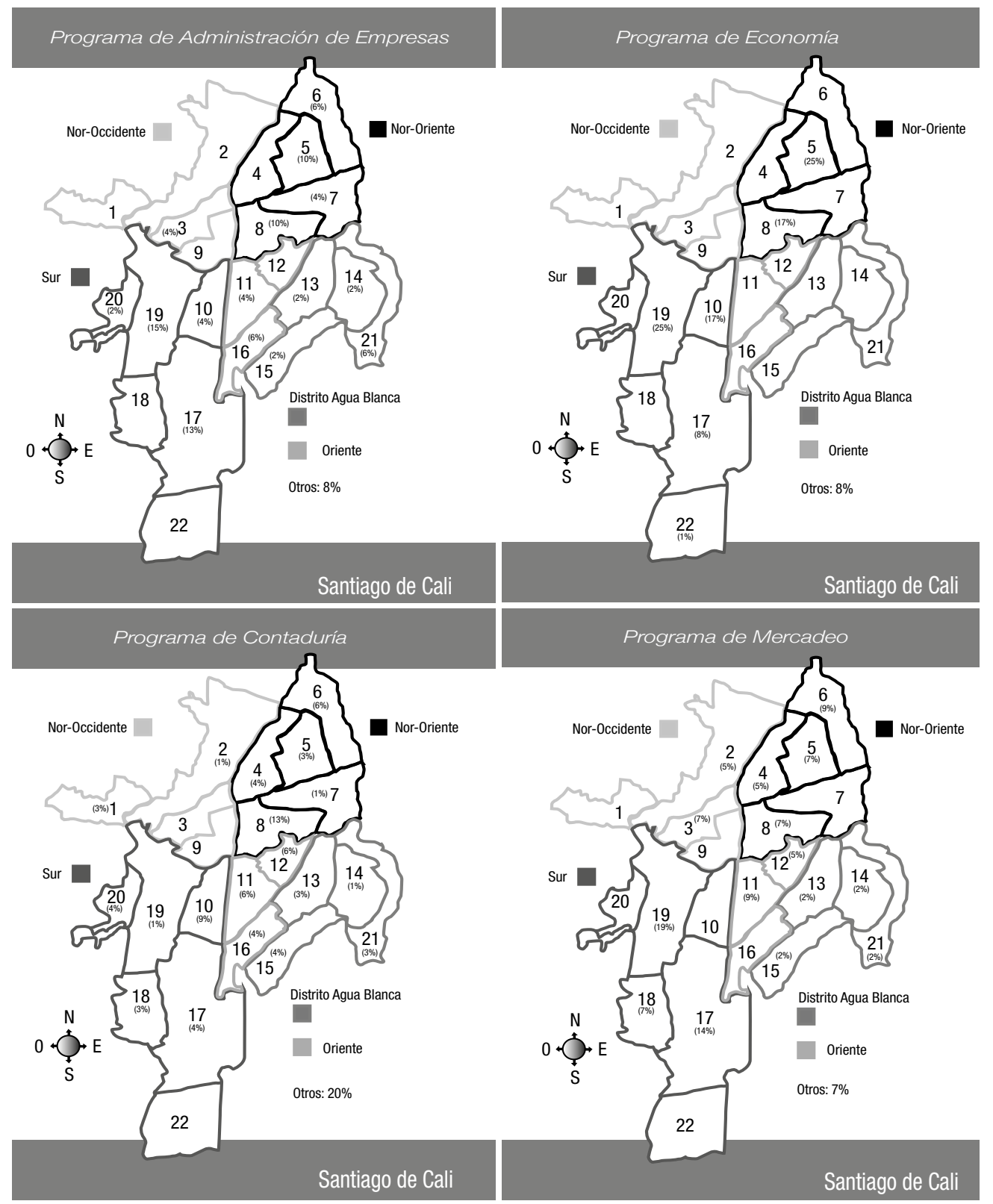

Figura 4. Facultad de Ciencias Económicas, Administrativas y Contables

Fuente: Encuesta estudiantes de pregrado primer semestre, período 2015-2, cálculos propios

Los estudiantes del Programa de Economía viven en las comunas 5 y 19 (25\%) cada una, seguido por la 8 y 10, ambas con $17 \%$ y el $8 \%$ correspondiente a la comuna 17 e igual porcentaje para estudiantes que se desplazan desde Palmira. 
Los estudiantes de Contaduría tienen su mayor frecuencia al oriente y nororiente de Cali (54\%) y el programa de Mercadeo con el 30\% provenientes del sector sur, de barrios como Caney, Limonar, Primero de Mayo, Samanes, Caldas, Meléndez, Miraflores, entre otros, seguido por el sector nororiente con el $28 \%$ y oriente $23 \%$.

En la Figura 5 se presenta el programa de Derecho con el mayor número de estudiantes provenientes de las comunas 17 (14\%), $19(11 \%), 6$ (9\%) y la 2 con 6 estudiantes, acumulando estas comunas el 54\%. Del Distrito de Aguablanca se presentan 12 estudiantes de los barrios El Diamante, Los Lagos, Robles, Ciudad Córdoba, Remansos, El Diamante y Talanga 4.

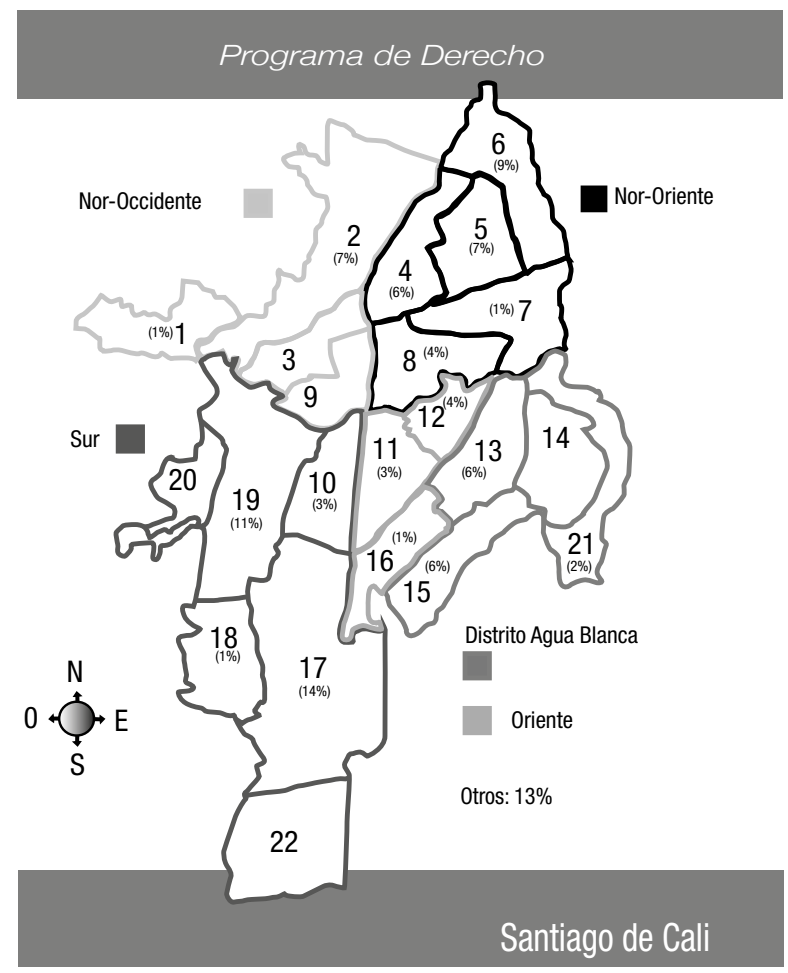

Figura 5. Facultad de Derecho

Fuente: Encuesta estudiantes de pregrado primer semestre, período 2015-2, cálculos propios

La Figura 6 muestra que Ingenierías de Sistemas e Ingeniería Industrial, presentan mayor frecuencia de estudiantes de la comuna 19, en Industrial el $41 \%$ viven en el sur y el $31 \%$ son del sector nororiental. Un estudiante de cada programa de Ingenierías dijeron ser desplazados. 

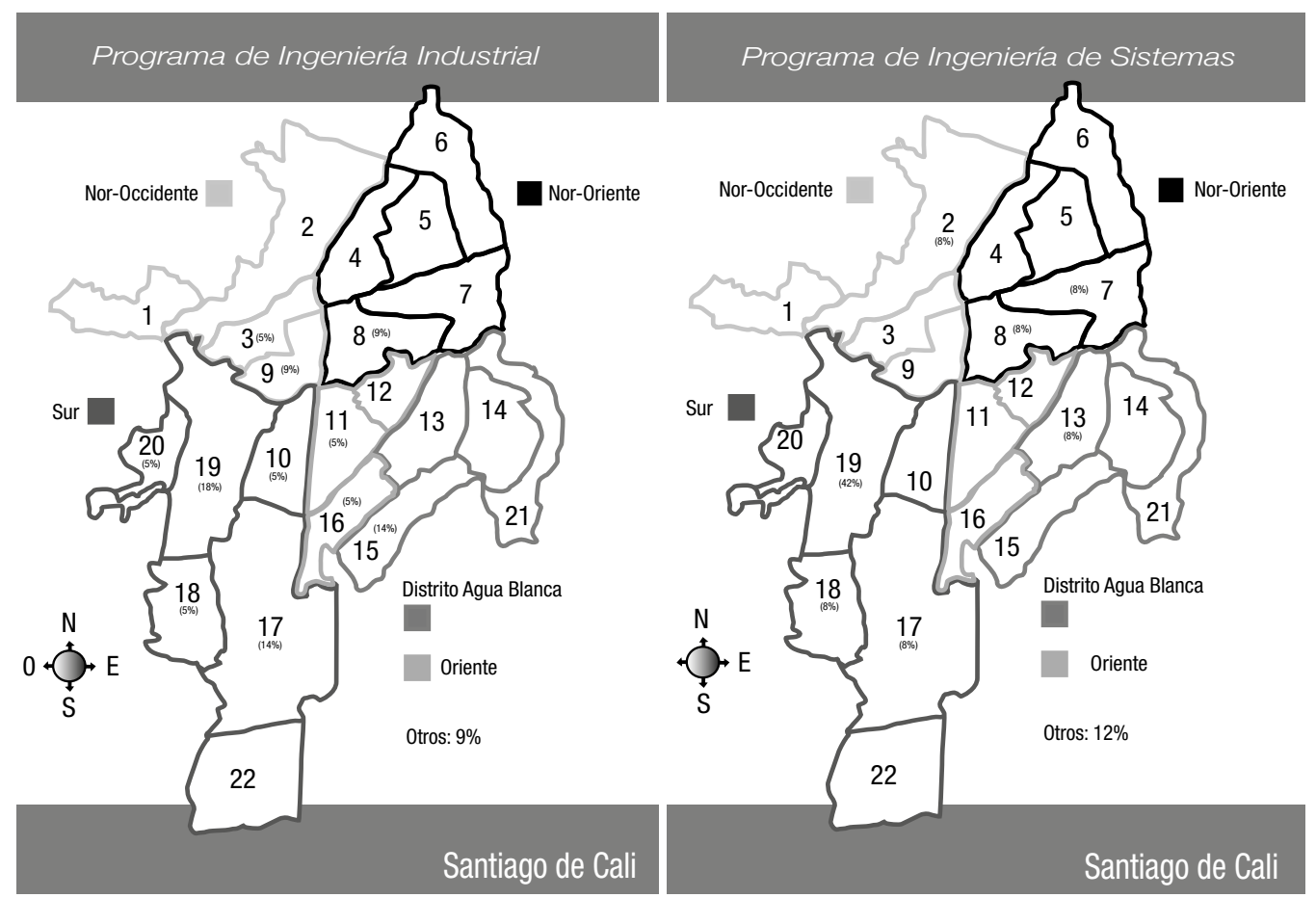

Figura 6. Programas de Ingenierías

Fuente: Encuesta estudiantes de pregrado primer semestre, período 2015-2, cálculos propio.

El programa de Medicina presenta mayor número de estudiantes provenientes de las comunas 17 y 19, acumulan entre ambas el 40\%, seguido por la comuna 2 del sector noroccidental (12\%); el 9\% se desplazan desde Candelaria, Florida, Jamundí y Palmira. Del distrito de Aguablanca solo se registra el caso de 1 estudiante del barrio Ulpiano Lloreda. En el programa de Enfermería el mayor porcentaje proviene de la comuna 17 (15\%), la 15 con el 11\%, sin embargo se presenta mayor concentración de estudiantes del oriente y sur de la ciudad ( $28 \%$ y $25 \%$ respectivamente), seguido por el nororiente con el $21 \%$ y el noroccidente con el 6\% (ver Figura 7). 

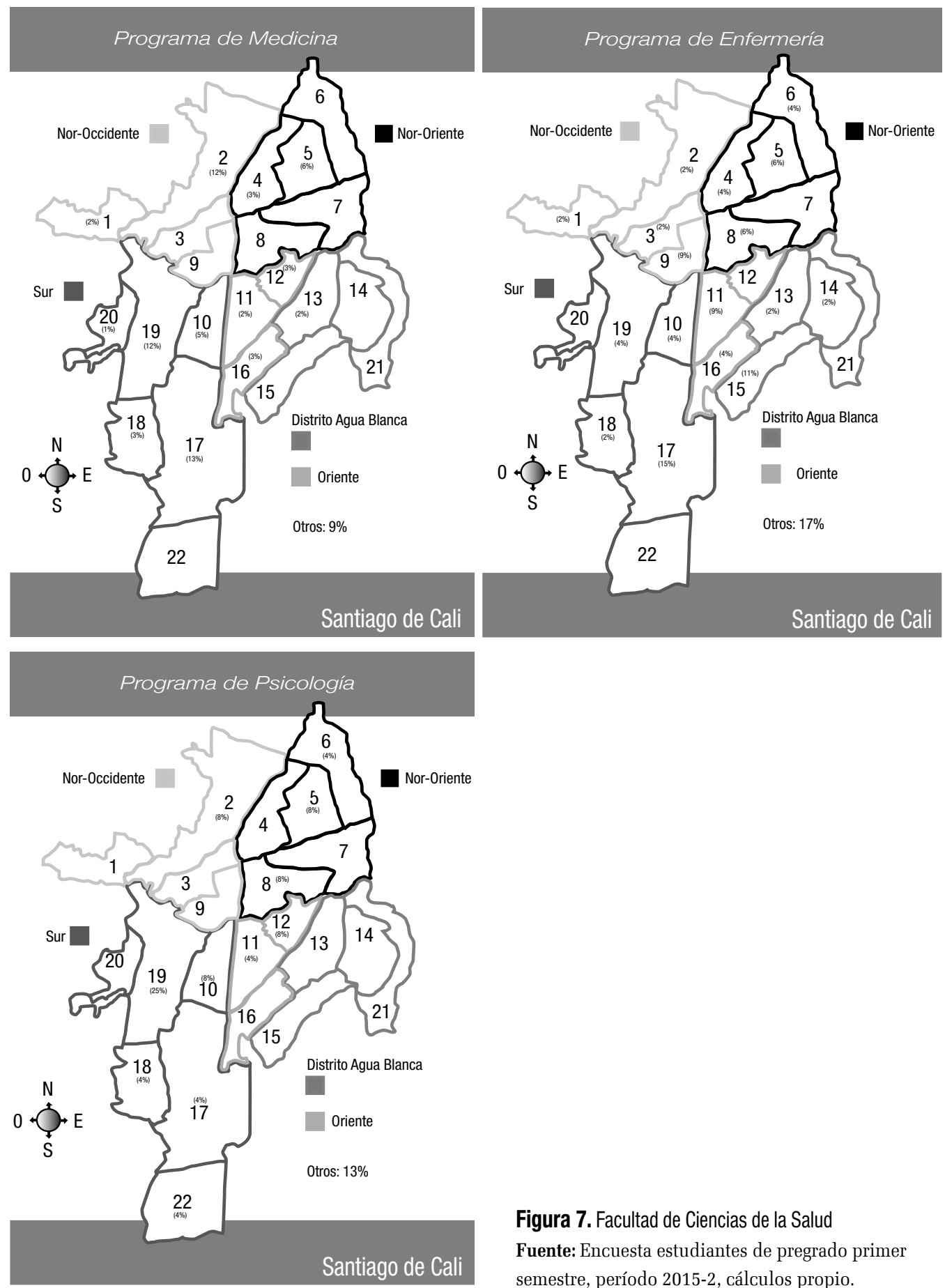

Figura 7. Facultad de Ciencias de la Salud Fuente: Encuesta estudiantes de pregrado primer semestre, período 2015-2, cálculos propio. 


\subsubsection{Género y situación laboral}

Para el segundo semestre del 2015, las mujeres que trabajan son 125 que representan el $23 \%$ de los encuestados y los hombres son 112, el 21\%. De los cuales se presentan mayores niveles de empleo (57\%) en el programa de Administración de Empresas y Mercadeo, los hombres, y las mujeres en Contaduría. Los menores niveles están en mujeres de Ingeniería de Sistemas ( $0 \%$ ), hombres y mujeres de Medicina ( $5 \%$ y $7 \%$ respectivamente), mujeres de Psicología, (12\%), seguidos de los hombres de Ingeniería de Sistemas (18\%). Un alto porcentaje de los encuestados de la Facultad de Ciencias de la Salud no dieron respuesta a esta pregunta o la contestaron de forma inadecuada, por esto no aplica (NA) es del $40 \%$ y $36 \%$ respectivamente para hombres y mujeres de Medicina y $29 \%$ para hombres de Enfermería. (Ver Figura 8).

Comparado con 2014-2, el 37\% de la población encuestada en ese año, respondió tener alguna actividad remunerada, el $21 \%$ corresponde a las mujeres y el $16 \%$ a los hombres. Los hombres de Enfermería y mujeres de Ingeniería de Sistemas son los que menos tienen renta propia.

Tener o no trabajo remunerado mientras se estudia, tiene varias connotaciones. Hay quienes afirman que esto no es lo mejor por cuanto el estudiante debe disponer del tiempo total para sus clases y tareas, pero también están quienes afirman lo contrario, bajo el argumento de que si el trabajo desempeñado por el estudiante está relacionado con su carrera, es bondadoso porque está adquiriendo también la práctica.

La mayoría de expertos concluyen que trabajar y estudiar tiene las siguientes ventajas: 1) no solo se logra una entrada de dinero sino que además puede ser una experiencia laboral valiosa, la primera tal vez, que puede derivar habilidades que le serán útiles no solo para otros trabajos sino además para otros aspectos de la vida. 2) Los estudiantes que trabajan medio tiempo obtienen experiencia profesional en medio de un ambiente de trabajo, y esto puede ser útil para los estudios de postgrado, puesto que podrá recibir cartas de recomendación y referencias sólidas. 3) Existen muchos trabajos en el campus mismo, y los beneficios de ello es que tienen flexibilidad de horarios donde los estudiantes pueden escoger el área de interés.

Como principal desventaja se tiene el riesgo de obtener un bajo rendimiento académico por las ocupaciones laborales y el costo de no disfrutar el ocio en la vida estudiantil, por esto, si bien el hecho que los estudiantes de una universidad trabajen mientras estudian puede garantizarles los ingresos vía pago de matrícula pero también puede colocar en riesgo su rendimiento académico y el desarrollo integral de la persona. 


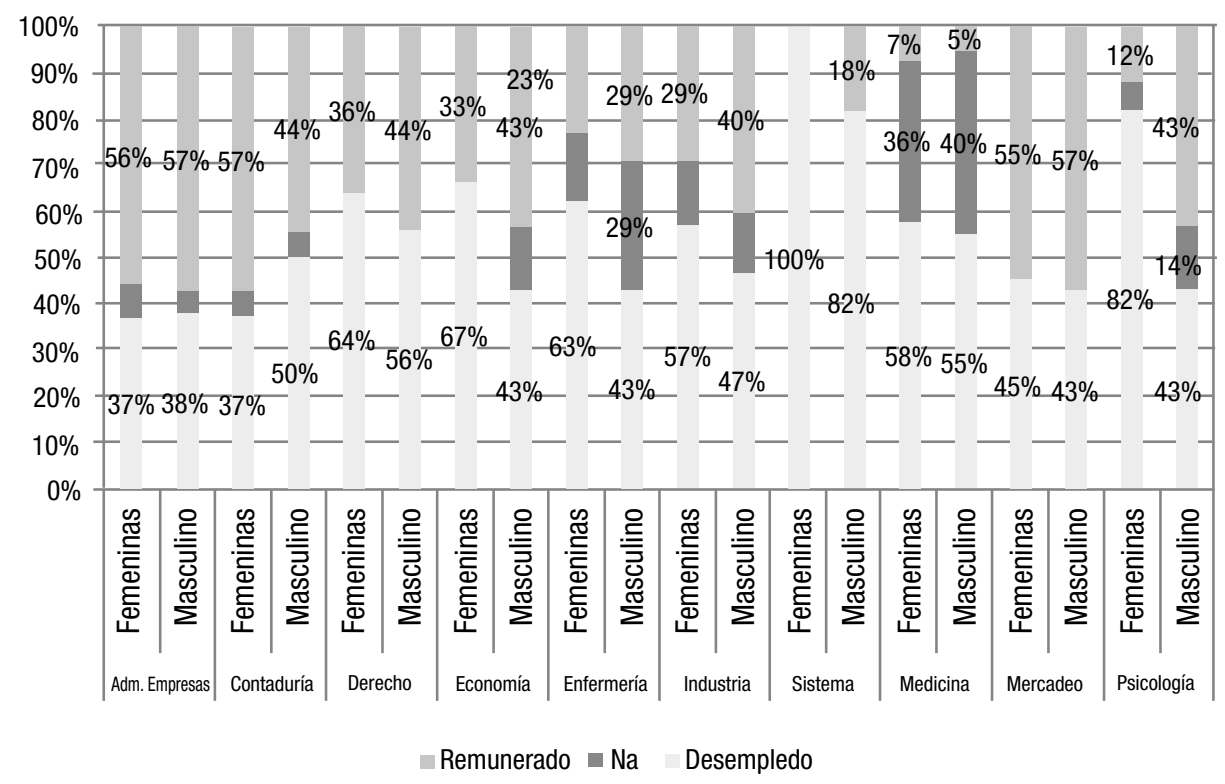

Figura 8. Relación entre género y situación laboral (\%)

Fuente: Encuesta estudiantes de pregrado primer semestre, período 2015-2, cálculos propios.

\subsubsection{Estado civil}

El 91\% de los encuestados manifiestan ser solteros, el otro 9\% está en unión libre, casado o separado, están solteros el 100\% de los matriculados en Ingeniería de Sistemas y Psicología, en Medicina el 98\%, entre 90\% y 95\% están los programas de la Facultad de Ciencias Económicas, aunque los demás programas en su mayoría también declaran estar solteros y en términos porcentuales superan el 50\%, en Derecho está en unión libre el 7\% y casado el $11 \%$; en el programa de Enfermería e Ingeniería Industrial se encuentran en unión libre el $6 \%$ y $5 \%$ respectivamente.

\subsubsection{Vivienda}

En 2015-2 el 67\% de los encuestados afirmaron tener vivienda propia. La mayor frecuencia de vivienda propia está en la Facultad de Ciencias de la Salud (78\%), pues el 83\% del programa de Medicina, 74\% en Enfermería y Psicología 71\% respondieron afirmativo a esta pregunta. Le siguen con vivienda propia, los programas de Economía 69\%, Contaduría e Ingeniería Industrial 64\% cada uno, Mercadeo 58\%, Administración de Empresas 56\% e Ingeniería de Sistemas con 36\%. Mientras que de los encuestados en 2014-2, el 65\% respondió tener vivienda propia. Del total de la población encuestada, 14\% estudiantes manifiestan estar pagando la deuda de su vivienda.

\subsubsection{Nivel educativo de los padres}

En la Figura 9 se observa la frecuencia del máximo nivel de estudios logrado por los padres de los encuestados, donde haber terminado secundaria es la mayor frecuencia (36\% madres 
y $31 \%$ padres), seguida del nivel profesional (21\% madres y 23\% padres), un número mayor de madres (9\%), respecto de los padres (7\%) ha logrado nivel de posgrado. (Ver Figura 9)

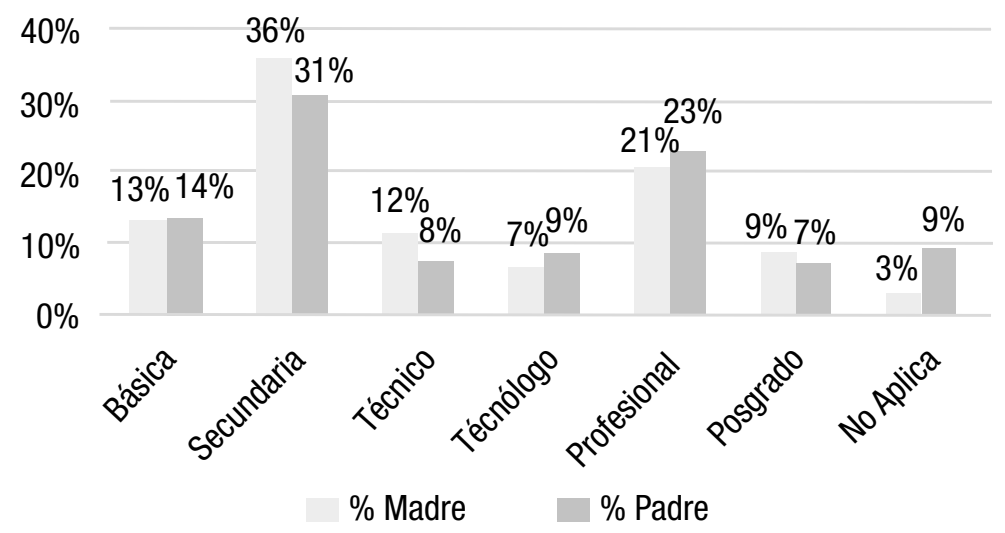

Figura 9. Distribución porcentual del nivel educativo de los padres

Fuente: Encuesta estudiantes de pregrado primer semestre, período 2015-2, cálculos propios

Analizando por programa se encuentra que Medicina con $38 \%$ y las Ingenierías, sistemas $42 \%$ e Industrial $27 \%$, presentan la mayor frecuencia de padres profesionales, este nivel de educación de los padres en los demás está entre el 30\% y el 40\%.

En el programa de Medicina, 23\% de padres ha alcanzado nivel de posgrado, seguido por Derecho e Ingeniería Industrial con el 9\%, Ingeniería de Sistemas con 8\%, 7\% en Enfermería, en Psicología y Administración de Empresas 4\%.

\subsubsection{Personas a cargo del estudiante}

Más de la mitad de los estudiantes encuestados refieren no tener ninguna persona a cargo, sin embargo, el $28 \%$ presenta responsabilidad alguna con 2 personas y es seguido por $1 \mathrm{a}$ cargo con el 15\%. El 48\% de los estudiantes de Medicina manifiestan un compromiso con dos personas, Enfermería (40\%), Mercadeo (37\%), 26\% en Derecho, 23\% en Administración de Empresas y Economía, los demás programas están entre el 16\% y 21\%.

El mayor porcentaje con una persona a cargo se da en Administración de Empresas con $21 \%$ y el $8 \%$ para los que tienen 3 personas bajo su responsabilidad, mismo compromiso para el 7\% de los estudiantes de Derecho.

\subsubsection{Religión}

Con respecto a la religión que practica la población estudiantil encuestada se observa que el $69 \%$ pertenece a la religión católica y el 15\% a la religión cristiana. El 9\% se declararon de otra religión o se abstuvieron de responder, el 3\% practican la religión evangélica, igual valor 
para los que no se consideran religiosos, y el $2 \%$ restante, le corresponde a religiones como adventistas, protestantes, Testigos de Jehová o judía en los que respondieron que suma el 1\%.

\subsection{VARIABLES SOCIOECONÓMICAS}

\subsubsection{Estrato}

Los encuestados en 2015-2 presentan mayor concentración en estrato 3 con 40\%, seguido del estrato 2 con $24 \%$ y el estrato 4 con $18 \%$, no obstante, cuatro programas se apartan de la media de la Universidad, es el caso de Medicina, que concentra su mayor frecuencia en el estrato 4 (31\%), seguido del estrato 5 (28\%), Psicología en estrato $3(38 \%)$, seguido del 4 $(33 \%)$, y las ingenierías Industrial y de Sistemas, tienen sus mayores frecuencias en estrato 3 seguido del estrato 4 , (Tabla 1 ).

\section{Tabla 1.}

Estrato Socioeconómico por Facultad/ Programa (\%)

\begin{tabular}{|c|c|c|c|c|c|c|c|c|}
\hline & \multicolumn{6}{|c|}{ ESTRATO } & \multirow{2}{*}{ NA } & \multirow{2}{*}{$\begin{array}{l}\text { Total \% } \\
\text { general }\end{array}$} \\
\hline & 1 & 2 & 3 & 4 & 5 & 6 & & \\
\hline FCEAC & $11 \%$ & $24 \%$ & $45 \%$ & $11 \%$ & $7 \%$ & $1 \%$ & $0 \%$ & $100 \%$ \\
\hline Admón Empresas & $8 \%$ & $15 \%$ & $52 \%$ & $13 \%$ & $10 \%$ & $2 \%$ & $0 \%$ & $100 \%$ \\
\hline Contaduría & $17 \%$ & $34 \%$ & $39 \%$ & $7 \%$ & $3 \%$ & $0 \%$ & $0 \%$ & $100 \%$ \\
\hline Economía & $0 \%$ & $23 \%$ & $46 \%$ & $15 \%$ & $8 \%$ & $8 \%$ & $0 \%$ & $100 \%$ \\
\hline Mercadeo & $9 \%$ & $19 \%$ & $49 \%$ & $14 \%$ & $9 \%$ & $0 \%$ & $0 \%$ & $100 \%$ \\
\hline FCS & $5 \%$ & $18 \%$ & $31 \%$ & $26 \%$ & $15 \%$ & $4 \%$ & $1 \%$ & $100 \%$ \\
\hline Enfermería & $9 \%$ & $28 \%$ & $43 \%$ & $17 \%$ & $2 \%$ & $2 \%$ & $0 \%$ & $100 \%$ \\
\hline Medicina & $3 \%$ & $12 \%$ & $20 \%$ & $31 \%$ & $28 \%$ & $6 \%$ & $0 \%$ & $100 \%$ \\
\hline Psicología & $4 \%$ & $17 \%$ & $38 \%$ & $33 \%$ & $4 \%$ & $0 \%$ & $4 \%$ & $100 \%$ \\
\hline FD & $4 \%$ & $33 \%$ & $39 \%$ & $16 \%$ & $7 \%$ & $1 \%$ & $0 \%$ & $100 \%$ \\
\hline Derecho & $4 \%$ & $33 \%$ & $39 \%$ & $16 \%$ & $7 \%$ & $1 \%$ & $0 \%$ & $100 \%$ \\
\hline INGENIERÍAS & $3 \%$ & $15 \%$ & $47 \%$ & $29 \%$ & $6 \%$ & $0 \%$ & $0 \%$ & $100 \%$ \\
\hline Ing industrial & $5 \%$ & $14 \%$ & $50 \%$ & $27 \%$ & $5 \%$ & $0 \%$ & $0 \%$ & $100 \%$ \\
\hline Ing Sistemas & $0 \%$ & $17 \%$ & $42 \%$ & $33 \%$ & $8 \%$ & $0 \%$ & $0 \%$ & $100 \%$ \\
\hline Total Universidad & $7 \%$ & $24 \%$ & $40 \%$ & $18 \%$ & $9 \%$ & $2 \%$ & $0 \%$ & $100 \%$ \\
\hline
\end{tabular}

Fuente: Encuesta estudiantes de pregrado primer semestre, período 2015-2, cálculos propios.

La consulta realizada en el año 2014 2, mostró que el 38\% de la población encuestada era del estrato 3, el de mayor frecuencia, seguido del 2, con excepción de dos programas académicos, Administración de Empresas e Ingeniería de Sistemas fueron mayoritariamente del estrato 2, seguido del 3. Solamente los matriculados al programa de Medicina eran de estrato $3(27 \%)$, seguidos del estrato 4 (24\%). Los estudiantes llegados para Administración 
de Empresas e Ingeniería de Sistemas son de estrato 2 principalmente, seguido del estrato 3 , (Tabla 2).

Esta tendencia de los matriculados hacia estratos más altos de la sociedad en 2015-2 puede tener varias lecturas, una, que el asunto es importante para las finanzas de la Universidad y sus posibilidades de incrementar los valores pecuniarios, pero al mismo tiempo está la posible pérdida del carácter popular de la Universidad.

Es posible que la ubicación de la Universidad en la nueva sede Valle del Lili genere algún desinterés a los aspirantes de estratos 2 y 3, de un lado por el mayor tiempo de recorrido dado su ubicación en el extremo sur de la ciudad y, de otro lado, por las expectativas de mayores costos en matrículas.

\section{Tabla 2.}

Estrato socioeconómico por programa 2014-2

\begin{tabular}{|l|l|l|l|l|l|l|l|c|}
\hline \multirow{2}{*}{ Estrato/Programa } & \multicolumn{7}{|c|}{ ESTRATO } & Natal \\
\cline { 2 - 7 } & $\mathbf{1}$ & $\mathbf{2}$ & $\mathbf{3}$ & $\mathbf{4}$ & $\mathbf{5}$ & $\mathbf{6}$ & & Programa \\
\hline Admón de Empresas & $19 \%$ & $30 \%$ & $26 \%$ & $19 \%$ & $0 \%$ & $4 \%$ & $4 \%$ & $100 \%$ \\
\hline Contaduría & $17 \%$ & $32 \%$ & $32 \%$ & $16 \%$ & $4 \%$ & $0 \%$ & $0 \%$ & $100 \%$ \\
\hline Derecho & $7 \%$ & $22 \%$ & $44 \%$ & $17 \%$ & $8 \%$ & $2 \%$ & $1 \%$ & $100 \%$ \\
\hline Economía & $7 \%$ & $32 \%$ & $36 \%$ & $21 \%$ & $0 \%$ & $4 \%$ & $0 \%$ & $100 \%$ \\
\hline Enfermería & $15 \%$ & $21 \%$ & $52 \%$ & $13 \%$ & $0 \%$ & $0 \%$ & $0 \%$ & $100 \%$ \\
\hline Ing. Sistemas & $7 \%$ & $50 \%$ & $21 \%$ & $7 \%$ & $14 \%$ & $0 \%$ & $0 \%$ & $100 \%$ \\
\hline Ing. Industrial & $11 \%$ & $26 \%$ & $47 \%$ & $13 \%$ & $3 \%$ & $0 \%$ & $0 \%$ & $100 \%$ \\
\hline Medicina & $8 \%$ & $17 \%$ & $27 \%$ & $24 \%$ & $13 \%$ & $11 \%$ & $0 \%$ & $100 \%$ \\
\hline Mercadeo & $0 \%$ & $27 \%$ & $38 \%$ & $20 \%$ & $13 \%$ & $2 \%$ & $0 \%$ & $100 \%$ \\
\hline Psicología & $0 \%$ & $23 \%$ & $58 \%$ & $12 \%$ & $8 \%$ & $0 \%$ & $0 \%$ & $100 \%$ \\
\hline Total Universidad & $9 \%$ & $25 \%$ & $38 \%$ & $18 \%$ & $7 \%$ & $3 \%$ & $0 \%$ & $100 \%$ \\
\hline
\end{tabular}

Fuente: Encuesta estudiantes de pregrado primer semestre, período 2014-2, cálculos propios.

\subsubsection{Financiación de estudios}

La mitad de la población que ingresa a la Universidad en 2015-2 afirma que requiere crédito para financiación de sus estudios, siendo el programa de Economía el de menor frecuencia (42\%) y Psicología el que más requiere, (67\%). La mitad de los encuestados para Ingeniería de Sistemas, Derecho, Contaduría y Mercadeo han tomado o están gestionando crédito para pagar sus estudios. (ver Figura 10). 
La financiación depende de la tasa de interés de mercado que se encuentra actualmente en una situación relativamente baja y estable, es necesario tener en cuenta los efectos de algunas medidas de política macroeconómica que pueden hacerla subir como es el caso de las políticas de control a la inflación y los efectos de aquellas variables relacionadas con el sector real de la economía como la disminución de la producción y el crecimiento económico, que generaría eventuales pérdidas de empleos, dificultando el acceso a crédito, dado que estar empleado representa un aval necesario para ser objeto de un préstamo en las instituciones financieras. Este aspecto se advierte como una de las posibles causas futuras de un incremento de la deserción.

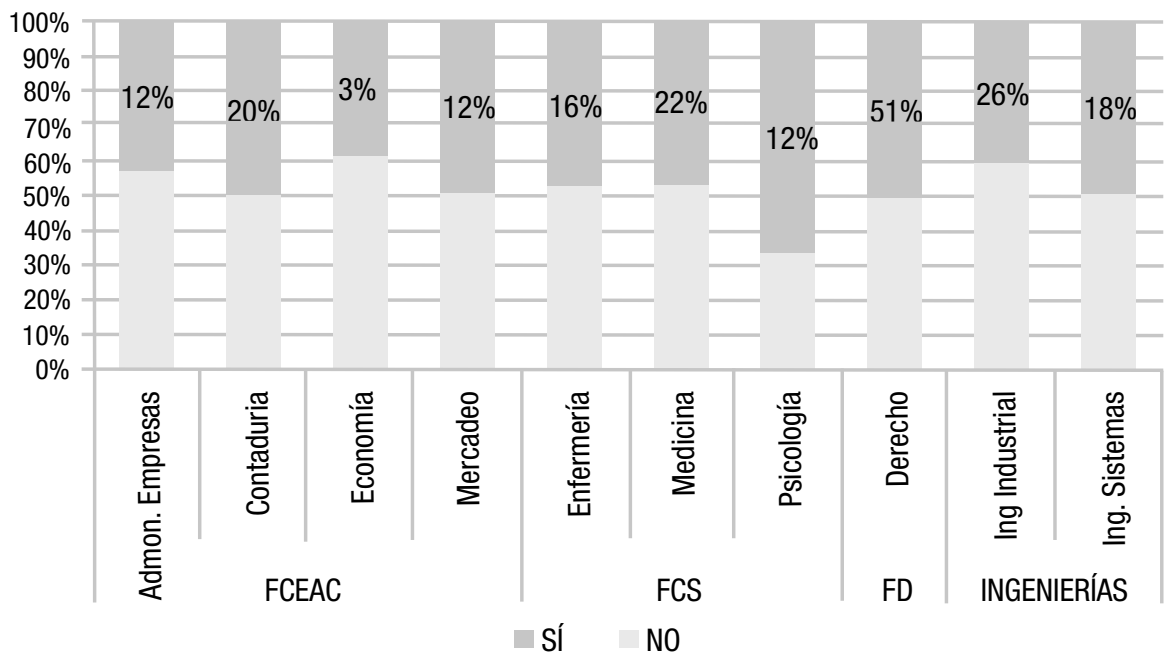

Figura 10. Financiación de estudios por Programa en la Facultad

Fuente: Encuesta estudiantes de pregrado primer semestre, período 2014-2, cálculos propios.

\subsubsection{Seguridad Social}

Para la Universidad Libre es de gran importancia conocer la cobertura en salud de los estudiantes, dado que este es uno de los requisitos de ingreso a la Institución. Como se puede observar en la Tabla 3, el 48\% de los encuestados tienen EPS, seguido por un 31\% que han marcado la opción No aplica.

EPS representa el más alto porcentaje de afiliación a la seguridad social, siendo la Facultad de Ciencias de la Salud la de mayor participación por parte de sus programas con el $60 \%$ (medicina 25\%, enfermería 24\% y psicología 11\%), seguida por la Facultad de Derecho con el $48 \%$. Mientras que de las categorías de SISBÉN, la de mayor participación se presenta en la Facultad de Ciencias, Económicas, Administrativas y Contables con el 10\%, correspondiendo el $6 \%$ de participación por parte del programa de Contaduría, y el 2\% para Administración de Empresas y Mercadeo (ver Tabla 3). 
Tabla 3.

Seguridad Social por Facultad/ Programa (\%)

\begin{tabular}{|l|c|c|c|c|c|c|c|c|c|}
\hline \multicolumn{1}{|c|}{$\begin{array}{c}\text { FACULTAD / } \\
\text { PROGRAMA }\end{array}$} & $\begin{array}{c}\text { SISBÉN } \\
\mathbf{1}\end{array}$ & $\begin{array}{c}\text { SISBÉN } \\
\mathbf{2}\end{array}$ & $\begin{array}{c}\text { SISBÉN } \\
\mathbf{3}\end{array}$ & $\begin{array}{c}\text { SISBÉN } \\
\mathbf{4}\end{array}$ & $\begin{array}{c}\text { SISBÉN } \\
\mathbf{5}\end{array}$ & EPS & $\begin{array}{c}\text { MEDICINA } \\
\text { PREPAGADA }\end{array}$ & $\begin{array}{c}\text { No } \\
\text { Aplica }\end{array}$ & Total \\
\hline FCEAC & $10 \%$ & $5 \%$ & $2 \%$ & $1 \%$ & $1 \%$ & $42 \%$ & $1 \%$ & $39 \%$ & $100 \%$ \\
\hline $\begin{array}{l}\text { Admón. } \\
\text { Empresas }\end{array}$ & $2 \%$ & $0 \%$ & $1 \%$ & $0 \%$ & $0 \%$ & $13 \%$ & $1 \%$ & $11 \%$ & $28 \%$ \\
Contaduría & $6 \%$ & $4 \%$ & $0 \%$ & $1 \%$ & $0 \%$ & $18 \%$ & $0 \%$ & $10 \%$ & $40 \%$ \\
Economía & $0 \%$ & $0 \%$ & $0 \%$ & $0 \%$ & $1 \%$ & $4 \%$ & $0 \%$ & $3 \%$ & $7 \%$ \\
Mercadeo & $2 \%$ & $1 \%$ & $1 \%$ & $0 \%$ & $0 \%$ & $7 \%$ & $1 \%$ & $14 \%$ & $25 \%$ \\
\hline FCS & $3 \%$ & $4 \%$ & $0 \%$ & $0 \%$ & $0 \%$ & $60 \%$ & $14 \%$ & $19 \%$ & $100 \%$ \\
\hline Enfermería & $1 \%$ & $1 \%$ & $0 \%$ & $0 \%$ & $0 \%$ & $24 \%$ & $3 \%$ & $4 \%$ & $35 \%$ \\
Medicina & $1 \%$ & $1 \%$ & $0 \%$ & $0 \%$ & $0 \%$ & $25 \%$ & $10 \%$ & $11 \%$ & $48 \%$ \\
Psicología & $1 \%$ & $1 \%$ & $0 \%$ & $0 \%$ & $0 \%$ & $11 \%$ & $1 \%$ & $3 \%$ & $18 \%$ \\
\hline FD & $7 \%$ & $7 \%$ & $2 \%$ & $1 \%$ & $0 \%$ & $48 \%$ & $7 \%$ & $29 \%$ & $100 \%$ \\
\hline Derecho & $7 \%$ & $7 \%$ & $2 \%$ & $1 \%$ & $0 \%$ & $48 \%$ & $7 \%$ & $29 \%$ & $100 \%$ \\
\hline INGENIERÍAS & $9 \%$ & $3 \%$ & $0 \%$ & $6 \%$ & $0 \%$ & $38 \%$ & $6 \%$ & $38 \%$ & $100 \%$ \\
\hline Ing industrial & $3 \%$ & $3 \%$ & $0 \%$ & $3 \%$ & $0 \%$ & $21 \%$ & $3 \%$ & $32 \%$ & $65 \%$ \\
Ing Sistemas & $6 \%$ & $0 \%$ & $0 \%$ & $3 \%$ & $0 \%$ & $18 \%$ & $3 \%$ & $6 \%$ & $35 \%$ \\
\hline Total general & $\mathbf{7} \%$ & $\mathbf{5} \%$ & $\mathbf{1} \%$ & $\mathbf{1} \%$ & $\mathbf{0} \%$ & $\mathbf{4 8} \%$ & $\mathbf{7} \%$ & $\mathbf{3 1 \%}$ & $\mathbf{1 0 0} \%$ \\
\hline
\end{tabular}

Fuente: Encuesta estudiantes de pregrado primer semestre, período 2014-2, cálculos propios.

El 10\% de los estudiantes del periodo 2015-2 del programa de Medicina tienen afiliación a medicina prepagada, seguida por el programa de Derecho con el 7\% de los encuestados. Los programas de Derecho, Medicina, Enfermería e Ingeniería Industrial tienen los más altos porcentajes de estudiantes afiliados a la EPS, mientras que el 39\% de los estudiantes de la FCEAC respondieron No aplica, siendo el programa de Mercadeo con el 14\% de las personas que no cuentan con ninguna de esta clasificación de seguridad social.

\subsubsection{Transporte}

El $70 \%$ de los encuestados se moviliza en transporte público. Su mayor demanda está en el programa de Psicología (88\%), seguido de Ingeniería Industrial, (86\%), Economía $(85 \%)$, Enfermería $(72 \%)$ y Medicina (68\%). El 30\% restante declaró que se desplaza en transporte privado. En la jornada diurna se presenta mayor demanda por el servicio público, 77\%, en la nocturna, 56\%, (ver Figura 11). 


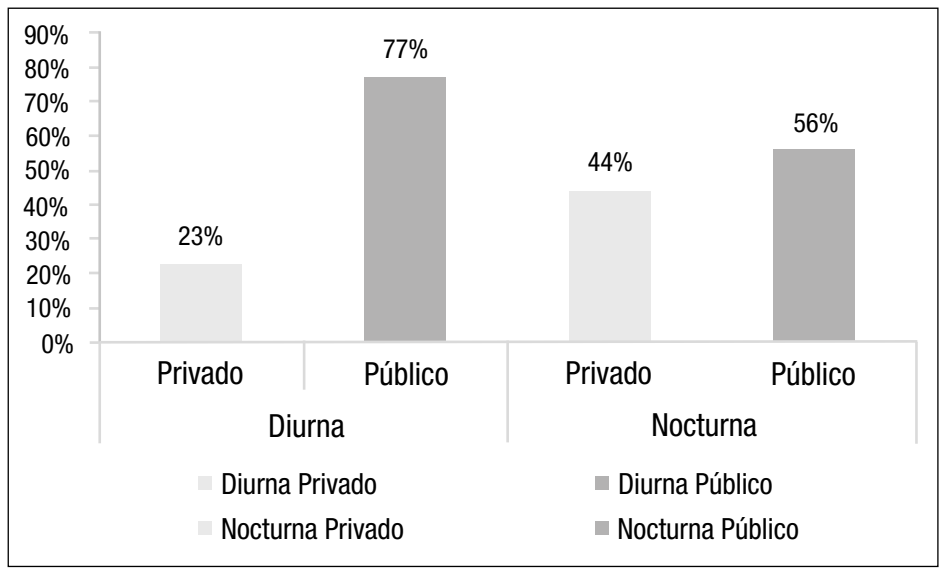

Figura 11. Transporte por jornada

Fuente: Encuesta estudiantes de pregrado primer semestre, período 2015-2, cálculos propios.

Visto por programas, Psicología, Ingeniería Industrial y Economía son los que presentan mayor uso del transporte público superando el 80\%, El programa de Mercadeo declara el mayor nivel de demanda de transporte privado (51\%) (ver Figura 12)

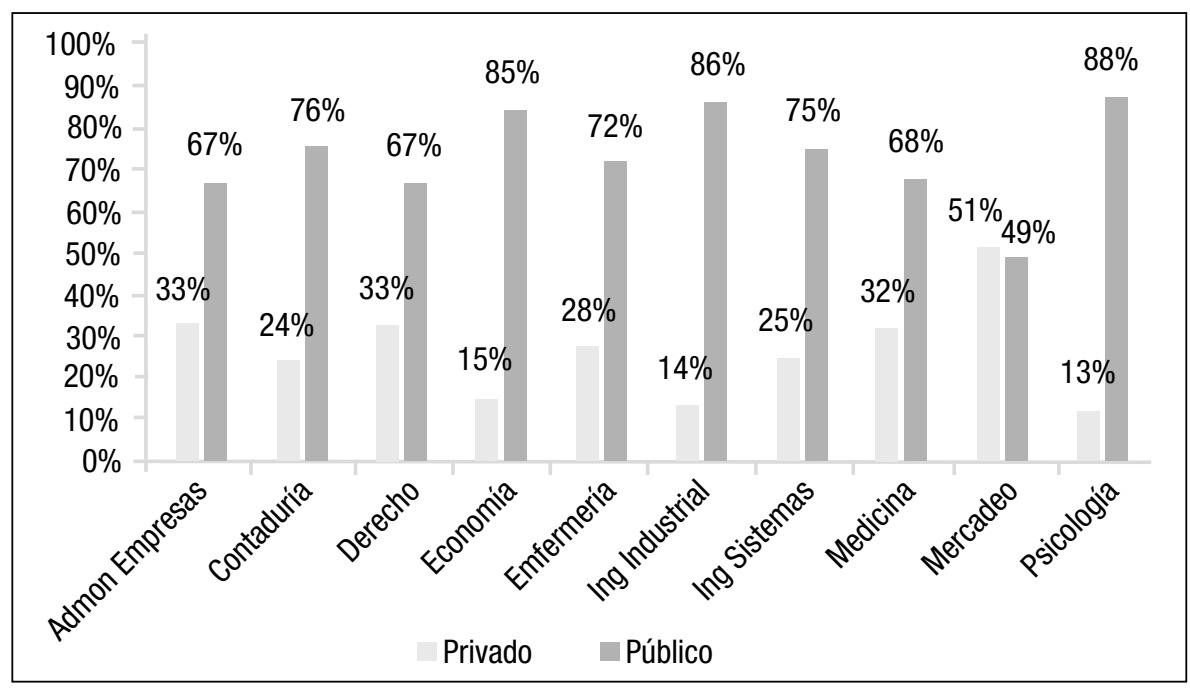

Figura 12. Transporte por programa

Fuente: Encuesta estudiantes de pregrado primer semestre, período 2015-2, cálculos propios.

La distribución de la demanda de transporte se asocia con la variable empleado, pues la mayor frecuencia de demanda de transporte privado se relaciona directamente con el número de encuestados que trabajan, las cuales están en el programa de Mercadeo y Administración de Empresas, lo que adquiere relevante importancia dentro del proceso 
de planeación de la Universidad y su traslado a la nueva sede, como quiera que allí se demandarán mayores niveles del transporte público e infraestructura para circulación de peatones y buses articulados.

\subsubsection{Dedicación en el tiempo libre}

En general, el 28\% de todas las Facultades dedican su tiempo a practicar un deporte, siendo la mayor preferencia (32\%) FCEAC, con mayor frecuencia en los programas de Administración de Empresas y Contaduría (ambas con el 10\%), seguida por la FCS con el $27 \%$ con mayor frecuencia de $13 \%$ en el programa de Medicina. Ingenierías con el 26\%, con mayor frecuencia en el programa de Ing. Industrial con el 15\%.

El 23\% de los estudiantes prefieren dedicar su tiempo a compartir con los amigos o el novio (a), siendo la FCEAC la de mayor preferencia con un $22 \%$ por compartir con amigos y $6 \%$ con el novio (a), para esta Facultad el programa de Mercadeo y Contaduría presentan la mayor frecuencia comparado con el total de toda la facultad.

\subsection{VARIABLES ACADÉMICAS}

\subsubsection{Carácter de la Institución del bachillerato}

Los estudiantes para el 2015-2 provienen en su mayoría de instituciones privadas (65\%) y lo restante de colegios públicos. El programa de medicina cuente con más estudiantes de colegios privados (83\%), mientras que los estudiantes del programa de contaduría provienen el 46\% de colegios públicos, muy cerca de la mitad. (Ver Figura 13)

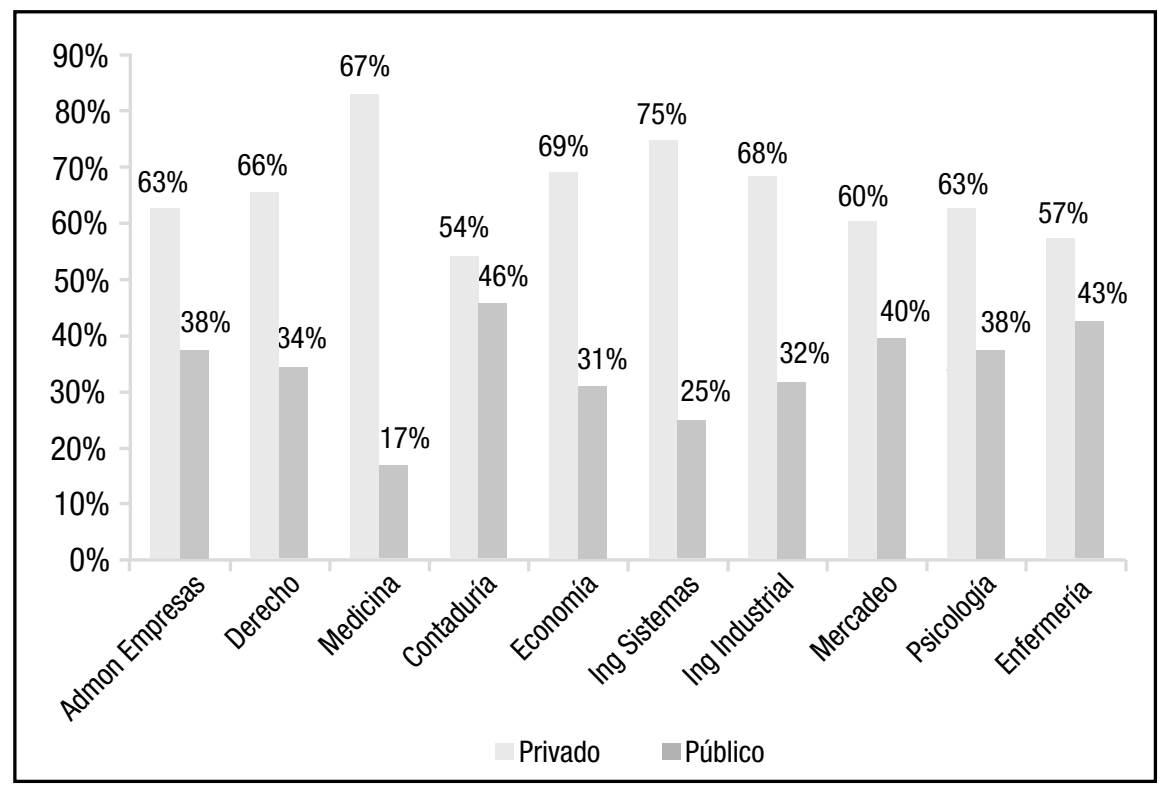

Figura 13. Carácter de la institución

Fuente: Encuesta estudiantes de pregrado primer semestre, período 2015-2, cálculos propios. 


\subsubsection{ICFES}

Los resultados en los exámenes de Estado para el ingreso a la educación superior, conocido como Pruebas ICFES, se utilizan para informar a la Universidad sobre el desempeño académico de los estudiantes en el bachillerato, para el documento se establece el ranking de la misma forma como el ICFES clasifica los colegios según los resultados generales de los exámenes.

De acuerdo con la evaluación, se determinan puestos en donde los primeros representan los puntajes más altos y los últimos puestos determinan los perfiles de puntos más bajos, rango entre 1 al 1.000; se dividió cada rango de resultados en 5 intervalos de clase y se clasificaron los estudiantes que ingresaron a la Universidad según el puesto asignado por el ICFES. (Ver Tabla 4)

\section{Tabla 4.}

Resultados pruebas ICFES de los estudiantes de la Universidad periodo 2015-2

\begin{tabular}{|c|c|c|c|c|}
\hline Rango & Clasificación & Fr & $\%$ & $\%$ acumulado \\
\hline 1 a 199 & Mejores bachilleres & 113 & $29 \%$ & $29 \%$ \\
\hline 200 a 399 & Buenos bachilleres & 124 & $31 \%$ & $60 \%$ \\
\hline 400 a 599 & Bachiller Promedio & 104 & $26 \%$ & $86 \%$ \\
\hline 600 a 799 & Bachiller regular & 39 & $10 \%$ & $96 \%$ \\
\hline 800 a 1000 & Bachiller muy regular & 15 & $4 \%$ & $100 \%$ \\
\hline \multicolumn{2}{|l|}{ Total } & 395 & $100 \%$ & \\
\hline \multicolumn{2}{|l|}{$\mathrm{Nd}$} & 39 & & \\
\hline \multicolumn{2}{|c|}{ Total general } & 434 & & \\
\hline
\end{tabular}

Como resultado de esta clasificación puede concluirse que el 29\% de los estudiantes que ingresaron en el periodo 2015-2 obtuvieron puntajes que los ubicaron entre los mejores bachilleres del país en sus respectivas promociones de bachillerato. El 31\% obtuvo puntajes altos y es el que mayor frecuencia presenta, clasificándose como buenos bachilleres. Sin embargo, de la proporción de estudiantes que ingresaron a la Universidad, el 14\% corresponde a puntajes que los ubican en desempeño regular.

En Ingeniería de Sistemas (45\%), Mercadeo (42\%) y Psicología (38\%) la mayor frecuencia se encuentra en los estudiantes que ocuparon los puestos entre 200 a 399; mientras que Medicina (71\%) y Enfermería (35\%) son los programas que presentan mayor periodicidad en los puestos del 1 al 199 indicando que ingresan estudiantes con clasificación de los mejores bachilleres.

En relación con los estudiantes admitidos que obtuvieron clasificación regular (puestos entre 600 y 799) o muy regular (entre 800 y 1000), el mayor porcentaje por programa lo tienen Administración de Empresas, Contaduría y Derecho. 


\subsubsection{Títulos obtenidos antes del pregrado}

La Universidad seccional Cali para el semestre estudiado, cuenta con estudiantes que previamente han realizado una carrera de estudios superiores siendo universitarios el $3 \%$, técnicos el 35\% y tecnólogos el 6\%.

\subsubsection{Capacidades excepcionales}

Para en 2015-2, se tienen 26 estudiantes que afirman tener alguna habilidad excepcional, (talento especial científico, subjetivo o tecnológico). Se destaca Mercadeo con 8 estudiantes, correspondientes a 5 con talento tecnológico y 3 con talento subjetivo, seguido por Derecho con 7, seis con talento subjetivo y 1 tecnológico. La Facultad de Ciencias Económicas Admistrativas y Contables cuenta con un total de 15 talentos, seguido por Derecho con 7, Medicina 2, para las carreras de Contaduría, Economía, Enfermería e Ingeniería Industrial, uno, cada una. (Ver Tabla 5).

En 2014-2, el número de talentos era de 20, 7 de Medicina, 4 de Derecho, de Contaduría, Enfermería e Ingeniería de Sistemas 2 de cada uno, y de Economía, Ingeniería Industrial y Mercadeo 1 de cada uno.

\section{Tabla 5.}

Talentos especiales

\begin{tabular}{|c|c|c|c|c|}
\hline Programa & Talento científico & $\begin{array}{c}\text { Talento } \\
\text { subjetivo }\end{array}$ & $\begin{array}{c}\text { Talento } \\
\text { tecnológico }\end{array}$ & Total \\
\hline Ing Sistemas & & & & 0 \\
\hline Psicología & & & & 0 \\
\hline Contaduría & & 150809 & & 1 \\
\hline Economía & & 152252 & & 1 \\
\hline Enfermería & & 155195 & & 1 \\
\hline Ing industrial & 154624 & & & 1 \\
\hline Medicina & $154931 ; 154958$ & & & 2 \\
\hline Admón. & 150069 & $150551 ; 150076$ & $150067 ; 150560$ & 5 \\
\hline Empresas & & $153461 ; 153413 ;$ & & 7 \\
\hline Derecho & & $153452 ; 153363 ;$ & 153367 & 7 \\
\hline Mercadeo & & $153753 ; 153403$ & & 8 \\
\hline Total general & 4 & $151897 ; 151537 ;$ & $151974 ; 151903 ;$ & $151968 ; 151544 ;$ \\
151967 & 14 & 8 & 26 \\
\hline
\end{tabular}

Fuente: Encuesta estudiantes de pregrado primer semestre, período 2015-2, cálculos propios. 


\section{Conclusiones}

Disponer de información ordenada y analizada resulta un baluarte para la planeación de toda institución, mucho más para la Universidad Libre Seccional Cali que se encuentra en la importante coyuntura de la terminación de la obra física de su nueva sede en el Valle del Lili, la programación de su traslado a la misma, lo que demanda análisis finos en materia de planeación académica, financiera y administrativa,

La ubicación de la vivienda de los estudiantes que residen en el municipio de Cali están distribuidos en el sector Sur, 36\%; en el que sobresalen dos comunas, la 17 (13\%), seguido por el sector nororiental (24\%) sectores oriente y noroccidente $9 \%$ en el Distrito de Aguablanca (comunas 13, 14, 15 y 21).

De los 434 encuestados el 37\% tienen alguna remuneración, en general, $40 \%$ son de estrato 3 , seguido del estrato 2 con $24 \%$, presentándose en algunos programas como

Medicina, su mayor frecuencia en el estrato 4 (31\%), seguido del estrato 5 (28\%), Psicología en estrato 3 (38\%), seguido del 4 (33\%), y las Ingenierías Industrial y de Sistemas, tienen sus mayores frecuencias en estrato 3 seguido del 4 . Esta tendencia hacia estratos más altos de la sociedad favorece las finanzas de la Institución y al mismo tiempo genera una posible pérdida del carácter social de la Universidad.

Medicina y Enfermería presentan mayor periodicidad en los puestos del 1 al 199 en pruebas Saber 11 indicando que admiten estudiantes con clasificación de mejores bachilleres. El mayor porcentaje de admitidos con clasificación regular (puestos entre 600 y 799) o muy regular (entre 800 y 1000), lo tienen Administración de Empresas, Contaduría y Derecho.

\section{Recomendaciones}

1. Para una mayor calidad y oportunidad de este tipo de estudio, se requiere contar con la información completa del aspirante desde el momento de su inscripción.

2. La Universidad puede recabar esta información mediante el diligenciamiento de un formato que sea verificado y complementado en el momento de la entrevista. Para lograr este objetivo se debe adelantar un proceso de capacitación a los docentes entrevistadores para revisar y completar el formato de encuesta con el entrevistado desde un computador conectado al sistema de la universidad.

3. La información resultante debe ser dispuesta en formatos que permitan hacer seguimiento a las variables entre varios períodos.

4. Las fechas de cierre de matrículas deben ser unificadas, puesto que cualquier rezago de uno o varios estudiantes genera distorsión.

\section{Equipo de trabajo}

El equipo de trabajo lo conforman: Héctor Zapata González, Harold Adolfo Erazo Barona, Mayra Alejandra Ortiz Bueno y las estudiantes auxiliares de investigación Sandra Viviana Pantoja Torres e Isabela Zapata Villegas del programa de Economía de la Universidad Libre Cali. 


\section{Agradecimientos}

Los autores agradecen la participación y apoyo con sus conceptos y suministro de información a los Ingenieros de Sistemas José David Guapacha y Eduardo Posso García, así como al profesor Diego García Muñoz por la lectura y sugerencias al documento final, al igual que al estudiante de Economía Andrés David Morales León por su ayuda logística.

\section{Conflicto de intereses}

Los autores declaran no tener ningún conflicto de intereses.

\section{Referencias bibliográficas}

1. Campos, E. (2012). Perfil socioeconómico de los estudiantes del Programa de Ingeniería Industrial de la Universidad Libre Seccional Barranquilla. Revista Ingeniare, 8 (14), 63-74.

2. Mora, C., Garcia, M, L., Galeano, C. (2000). Voces y Rastros de Jóvenes Javerianos. Cali: Pontificia Universidad Javeriana - Cali.

3. Garcia, A. (2008). El perfil socioeconómico del estudiante que ingresa a la Universidad Libre - Seccional Cali. Revista Libre Empresa, 5 (2) 45-109

4. Genecco, Á. M., Díaz J., Raigosa M., Marulanda L. (2007). Perfil socioeconómico y demográfico de acceso a la carrera de antropología y sociología-Universidad de Caldas primer semestre de 1.998 y segundo periodo de 2.005 .

5. Acevedo, S., Jaramillo, A. (2007). Perfil Socioeconómico de los estudiantes de pregrado de EAFIT-2.007. Universidad EAFIT, Medellín 2007.

6. Universidad Autónoma de Occidente - Cali (2007). Perfil socioeconómico del estudiante autónomo-2.007. Cali: Oficina de Planeación y Desarrollo InstitucionalBienestar Universitario.

7. Universidad de Pamplona Oficina de Planeación (2012). Características del Perfil Socioeconómico del Estudiante de Pregrado de la Universidad de Pamplona. Editorial Universitaria.

8. Rico, D. A. (2005). Perfil socioeconómico de los estudiantes - Medellín 2.005 Oficina de Planeación - Universidad Nacional de Colombia: Medellin.

9. Centro de Investigaciones. Departamento de Bienestar Universitario. (2005). CARACTERIZACIÓNDELOSESTUDIANTESDEUNA INSTITUCIÓNDEEDUCACIÓN SUPERIOR DE PEREIRA. Investigaciones Andina, 7(10) 10-16. Recuperado de http:// www.redalyc.org/articulo.oa?id=239017675003

10. Orduz, M. (2009). Caracterización del estudiante de la Universidad de Cundinamarca para el diseño de un modelo de Bienestar universitario. Esquemas universitarios, 9. 